\title{
Interdisciplinary and collaborative design at the core of inquiry and scholarly research
}

\author{
Daniel K. Brown, Mark Southcombe \\ Victoria University of Wellington, New Zealand \\ School of Architecture \\ daniel.brown@vuw.ac.nz | mark.southcombe@vuw.ac.nz
}

In professional practice, design operates as both a research method and a final outcome. Academic researchers in design disciplines tend, however, to privilege process.' The same conflict is evident in the academic arena, where students often struggle to differentiate design as process from design as the end result. Design in this sense is an iterative process with a contingent endpoint. Pretty and McPherson's essay describes the conflict that results in the classroom when the word "design" is treated as both a verb and a noun. According to their essay:

This morphing of the word [design] to encompass so much has led to an apparent designwashing akin to the so called green-washing / eco-sustainability washing of disciplines which has become an enormous taxonomy problem for not only the designer but also for the general populace.

Abbot and Bowring proactively confront the dual meaning of the word "design" through engagement in interdisciplinary and collaborative live projects. Their research is conceived as "design as laboratory" or "experimental practice" - exploring the "terrains of possibility" by applying tools of questioning, collaborating, designing, grounding and communicating. In so doing, the design method and the design outcome support one another as research loop.

\footnotetext{
I "As a working definition, architectural design research can be described as the processes and outcomes of inquiries and investigations in which architects use the creation of projects, built or unbuilt, or else broader contributions towards design thinking, as the central constituent in a process which also involves the more generalized research activities of thinking, writing, testing, verifying, debating, disseminating, performing, validating, etc." Murray Fraser, "Design Research in a Globalised age," in Architectural Design Research Symposium, ed. Jules Moloney, Simon Twose, and Jan Smitheram (Wellington: Victoria University Press), 24.
} 
Design as laboratory invokes a science model, emphasising collaboration and collective research, where different research teams work on key aspects of shared questions. ... The concept of the lab draws on science as a model, particularly in recognising the potency of cooperative and collective research activity.

And academics benefit when time formally accounted for as teaching can simultaneously and strategically be recognised as research led with a range of design project outcomes addressing a shared problem or question.

Communities and academic institutions both benefit in significant ways when interdisciplinary and collaborative live projects become the prevailing mode of learning within architecture and design curricula. Abbott and Bowring refer to these benefits as engaging: "the 'knight's move' - the oblique operation where things not linearly connected are combined in unexpected ways."

Providing benefit to a community offers unique learning opportunities for students. Cerulli refers to this as a "drive towards social realism in architectural education." Students in her case studies enhanced community facilities and developed community economies by engaging in real time projects with real time budgets. Pretty and McPherson describe three years of live student projects that benefited the community by rejuvenating Christchurch after the devastating earthquakes of 2010 and 2011 within the context of the Festival of Transitional Architecture (FESTA). Marriage describes a live project that extends and applies research to showcase to the community and the students the importance of sustainability. And Abbott and Bowring describe interdisciplinary and collaborative live projects that enrich the community through environmental initiatives as well as by embedding significant cultural references.

Mclntosh and Marques look closely at the cultural challenges of engaging live projects - in this case, within Māori and Pasifika communities. When cultural issues are at the forefront of a live project, collaboration is absolutely essential. For such projects to be successful, community members must be able to participate in an empowering design process that incorporates "understanding, relationships, respect and participation." The student is no longer the designer, but instead becomes a facilitator for collaborative design. This role transformation also increases the leadership capacity of both the student and the community, empowering the community as a collective. And the concept of interdisciplinarity takes on new meaning; students learn that the community members themselves represent diverse "disciplines," bringing different knowledge bases into play. By conceiving live projects that are both interdisciplinary and collaborative, research methods directly parallel contemporary architectural design practices. Pretty and McPherson present three years of case studies of large scale interdisciplinary and collaborative "live build projects" for FESTA in Christchurch. As temporary installations, they helped students understand the "heuristic design processes that are an integral part of a prospective architect's arsenal of skills." Guy Marriage, in his essay, describes a live student project that represents the other end of the interdisciplinary and collaborative spectrum - one that parallels professional practice, where the end product can be rigorously tested as sustainable habitation. He describes a university-led interdisciplinary student team project that involved researching, designing, building and operating a solar-powered house for the Solar Decathlon Competition. As an international competition seeking innovative 
new solutions, students came to understand how research can help disperse disciplinary boundaries and invite radically new and unexpected solutions. In the case of Pretty and McPherson's projects for FESTA, as well as Marriage's Solar Decathlon project, the opportunity to produce a project within the public realm was a significant driving force in solidifying student engagement at the highest level. Marriage's project had the added incentive of being an international competition. To win the competition required significant collaboration between team members who had to rapidly accumulate specialised knowledge from diverse fields. And this significantly enhanced the diversity of the learning experience.

All of the essays in this chapter recognise that the academic arena needs to evolve in order for interdisciplinary and collaborative live projects to flourish. Marriage notes that significant difficulties arise when an interdisciplinary live project has a wider scope than typically allowed for in the traditional academic arena. Without greater flexibility in the curriculum, such projects can face overwhelming challenges, particularly when students need to miss other courses in order to fully engage with the live project. But the realisation that live projects are interdisciplinary can provide an academic incentive for such projects to be viewed within the curriculum as reflecting the learning objectives targeted by multiple courses. With this in mind, a curriculum can be reconceived to enable interdisciplinary and collaborative live projects to take on far greater roles in design education.

Cerulli's essay reflects on the difficulties faced when a live project is assigned to students and the academic also has professional interests in the manner of a project architect or responsibility to a client, as also often occurs with guest professionals teaching in a university programme. Cerulli refers to this as the "ambiguous and multifaceted nature of the designer educator." The client of a live project can have concerns about the nature of the end result, and the academic institution can have concerns about potential conflicts of interest for the academic. But both the architectural practice and the client can ultimately benefit; student design concepts provide a wider range of ideas without adding to the financial burden of the project, and they can facilitate discussion around a potential civic or community project. Students' future employability also benefits from having had actual work experience. Cerulli argues such projects should be seen as representing a "conflux of interests" where interests converge rather than separate. She argues that a "new vocabulary is needed to articulate the complexities of interdisciplinary and collaborative live projects at the intersection of academic research, professional practice and teaching and learning, but also to describe the confluxes of interests that might underpin them." This is a valuable rethinking of the ethics and conduct issues associated with interdisciplinary and collaborative research, where the interests held by different participants rarely exist neatly in parallel. They diverge, converge, overlap or may exist at a distance. It is the connections, overlaps and conflux in interests that result in shared projects. The implications for project framing, definitions of responsibilities and roles, and deliverables are clear. Clarity over potentially shared ownership and use of intellectual property also emerges as an issue for research outputs, but also for professional inputs and resourcing to university programmes.

The essays in this chapter demonstrate that design research methods are diverse and deliver equally diverse outcomes. These outcomes add value to university teaching having impact on both the student learning experience and the wider host / promoters' 
programme and context. Interactive and collaborative design-led research practices with their focus on both student learning outcomes and the effects of their design outcomes typically balance emphasis on process and outcomes. Both processes and outcomes have significant impact on their community contexts through the discourse generated from embedded participatory processes, exhibition and publication. The challenge for design academics is to find a direction that "charts a course for a strengthening and more strategic role for design that is located at the core of inquiry and scholarly research," as noted by Abbott and Bowring. The evidence in the papers within this chapter of the book suggests this will be through increased interdisciplinary and collaborative design-led research.

\section{To cite this article:}

Brown, D. K. and Southcombe, M. (2017), Interdisciplinary and collaborative design at the core of inquiry and scholarly research. The Journal of Public Space, 2(3), Special Issue, 7-10, DOI: 10.5204/jps.v2i3. 107

This article has been accepted for publication in The Journal of Public Space. Please see the Editorial Policies under the 'About' section of the journal website for further information.

(c) This work is licensed under a Creative Commons Attribution - Non Commercial 4.0

BY NC International License https://creativecommons.org/licenses/by-nc/4.0/ 